\title{
MODEL OF LEADERSHIP AND ENTREPRENEURIAL INTENTIONS AMONG EMPLOYED PERSONS
}

\author{
Mali, P. ; Kuzmanovic, B. ${ }^{* *}$; Nikolic, M. ${ }^{* * *}$; Mitic, S. ${ }^{* *} \&$ Terek, E. ${ }^{* * *}$ \\ *University of Belgrade, Faculty of Economics, Belgrade, Serbia \\ ** University of Novi Sad, Faculty of Technical Science, Novi Sad, Serbia \\ *** University of Novi Sad, Technical Faculty “Mihajlo Pupin”, Zrenjanin, Serbia \\ E-Mail: predragmali@yahoo.com, kbogdan@uns.ac.rs,mikaczr@sbb.rs, smitic@uns.ac.rs, \\ terekedita@gmail.com
}

\begin{abstract}
The paper presents the results of the study of the influence of leadership dimensions, (transformational, transactional, LMX and ethical leadership) on individual entrepreneurial orientation dimensions, the achievement dimension and the theory of planned behaviour dimensions. The respondents were employed persons in organizations in Serbia (540 respondents). Under favourable conditions (good strategic management and intellectual stimulation), entrepreneurial intentions tend to decline, while under unfavourable conditions (expectation of high performance with punishment as motivation), entrepreneurial intentions tend to increase. The leader's unethical behaviour can lead to great dissatisfaction among employees, who then begin to form entrepreneurial intentions, even if they do not have such a positive opinion of entrepreneurial ventures. A general model, of the impact of the observed leadership dimensions on two particularly significant entrepreneurial dimensions: Personal Attitude and Entrepreneurial Intentions, is formatted, as well as a model of those influences in the case of the moderating effect of the respondents' perceived performance at work.

(Received in November 2018, accepted in June 2019. This paper was with the authors 2 months for 2 revisions.)
\end{abstract}

Key Words: ～Leadership, LMX, Ethical Leadership, Entrepreneurial Intentions, Model

\section{INTRODUCTION}

Previous research in the field of entrepreneurial intentions has not been sufficiently focused on entrepreneurial intentions among employees, in terms of external entrepreneurial intentions: the situation in which employed persons leaves their jobs and begin their own entrepreneurial ventures. Similar observations are made in the references [1, 2], which states that, up to now, the research into entrepreneurial intentions among employed persons has been largely overlooked.

In this paper, attention is focused on the examination of the influence of leadership (transformational, transactional, LMX and ethical leadership) on the entrepreneurial intentions of the employed. A number of studies examine the relationship between leadership and intentions to leave the organization $[3,4]$, then the LMX relationship with intent to leave organizations $[5,6]$, as well as the ethical leadership link with the intention to leave the organization $[7,8]$. Thus, a number of studies show the significant impact of different aspects of leadership on employees' intentions to leave the organization. It should be emphasized here that these studies refer to the intention to leave the organization in general, and that this is not necessarily related to entrepreneurial intentions or intentions to leave in order to open up one's own company.

When it comes to organizations in Serbia, as the subject of research in this paper, it should be noted that some previous research studies in Serbian organizations $[9,10]$ show a certain degree of employee dissatisfaction. The causes of such situations are usually related to low income, and dissatisfaction with leadership and organizational culture. Such circumstances can easily encourage the development of entrepreneurial intentions among employees. 
In this paper, the problem of research is the examination of the influence of leadership dimensions (transformational, transactional, LMX and ethical leadership) on individual entrepreneurial orientation dimensions, the achievement dimension and the theory of planned behaviour dimensions. Additionally, in the analysis of the observed relationships, one moderator is involved: the respondents' perceived success at work. Also, the aim of the research is to model those influences. The significance of the research lies precisely in determining the impact on entrepreneurial attitudes and intentions among employees.

\section{THEORY AND RESEARCH QUESTIONS}

\subsection{Individual entrepreneurial orientation}

The concept of Entrepreneurial Orientation (EO) was developed by Miller [11]. This concept originally consisted of three dimensions: risk-taking, innovativeness and proactiveness. According to [12], lately the concept of entrepreneurial orientation (EO) is often transferred from the level of the organization to the individual level. This creates the concept of individual entrepreneurial orientation (IEO). These two concepts are essentially similar, making such a change in the level of their observation possible. Thus defined and set, the concept of individual entrepreneurial orientation is easily used to examine the impact of the dimensions that form it (risk-taking, innovativeness, proactiveness) on the entrepreneurial intentions of individuals.

\subsection{The need for achievement}

The need for achievement is the leading motive, which determines the level of entrepreneurial activity. The need for achievement, unlike willingness to take risks, is important not only for launching an entrepreneurial venture, but also for its long-term survival and development. Thus, according to [13], the motivation for achievement is good both for starting a business and for its long-term success. The motivation for achievement is one of the key entrepreneurial competencies [14-17].

\subsection{The theory of planned behaviour}

The theory of planned behaviour (TPB) is a model that explains entrepreneurial intentions, and was developed by Ajzen [18]. The TPB model consists of three components (motivational factors, predictors), which anticipate the emergence of intentions (including entrepreneurial ones). These components are: (1) Personal Attitude (attitude towards entrepreneurship and entrepreneurial behaviour), (2) Subjective Norm and (3) Perceived Behavioural Control. As the fourth component, Entrepreneurial Intention is precisely observed.

Three research questions were set:

RQ1: Is there a statistically significant influence and predictive effect of the leadership dimensions (transformational and transactional leadership) on individual entrepreneurial orientation dimensions, the achievement dimension and the theory of planned behaviour dimensions?

RQ2: Is there a statistically significant influence and predictive effect of the leadership dimensions (LMX and ethical leadership) on individual entrepreneurial orientation dimensions, the achievement dimension and the theory of planned behaviour dimensions?

RQ3: Is there a moderating effect of the respondents' perceived success at work on the relationship between the leadership dimensions and individual entrepreneurial orientation dimensions, the achievement dimension and the theory of planned behaviour dimensions? 


\section{METHOD}

\subsection{Survey instruments (measures)}

The Individual Entrepreneurial Orientation Instrument (IEOI) [19] was used to measure individual entrepreneurial orientation. The instrument consists of 10 items, which are arranged in 3 dimensions: 1. Risk-taking, 2. Innovativeness and 3. Proactiveness. The respondents made their evaluations on a seven-point Likert scale.

To measure the need for achievement, the Attitude Toward Enterprise (ATE) Test [20] was used. To be more precise, a single dimension from this instrument - the Achievement dimension, was employed. The dimension comprises 4 items. The respondents recorded their evaluations on a seven-point Likert scale.

The Entrepreneurial Intention Questionnaire (EIQ) [21] was used to measure the theory of planned behaviour dimensions. The instrument has 20 items, which are organised into 4 dimensions: 1. Personal Attitude, 2. Subjective Norm, 3. Perceived Behavioural Control and 4. Entrepreneurial Intentions. The respondents made their evaluations on a seven-point Likert scale.

Transformational leadership was measured using the Transformational Leadership Behaviour Inventory (TLI) [22]. The questionnaire consists of 14 items, which make up the 4 dimensions of transformational leadership. The respondents rated the items on a seven-point Likert scale. The dimensions are: 1. Core Transformational Leader Behaviour, 2. High Performance Expectations, 3. Supportive Leader Behaviour and 4. Intellectual Stimulation. Transactional leadership was measured through two dimensions: 1. Contingent Reward Behaviour and 2. Contingent Punishment Behaviour [22].

The LMX ratio was measured using an instrument [23]. This is a four-dimensional questionnaire for measuring the LMX relationship. The questionnaire consists of 12 items, which make up 4 dimensions. The respondents evaluated the items on a five-point Likert scale. The dimensions are: 1 . Affect (to what extent the employees like their leader as a person), 2. Loyalty (to what extent the leader offers employees support), 3. Contribution (willingness to do more than meet the basic requirements and expectations because of the leader) and 4. Professional Respect (the existence, recognition and respect of the leader's knowledge and competencies by the employees).

Ethical leadership behaviour was measured using the Ethical Leadership Scale [24]. The questionnaire consists of 10 items, which make up one dimension. The respondents evaluated the items on a five-point Likert scale.

\subsection{Participants and data collection}

The research was carried out in organizations in Serbia. Medium and large organizations were observed and the sample included production, service and public organizations. In terms of the ownership structure, both state and private organizations were observed. The respondents were employed in these organizations and were of mixed gender, age, level of education (minimum secondary school) and position in the organization. The final sample consists of 540 respondents. The research involved 72 organizations.

\section{RESULTS}

\subsection{Descriptive statistics}

Table I provides the descriptive statistics for the observed dimensions and the respondents' perceived success at work item. The values of Cronbach's alpha are in the range from 0.792 to 0.961 . 
Table I: Descriptive statistics for the observed dimensions and the perceived success at work item.

\begin{tabular}{|l|c|c|c|c|c|c|c|}
\hline \multicolumn{1}{|c|}{ Names of dimensions and items } & Abbr. & $N$ & Min & Max & Mean & $\begin{array}{c}\text { Std. } \\
\text { dev. }\end{array}$ & $\alpha$ \\
\hline Risk-taking & RT & 540 & 1,00 & 7,00 & 4,596 & 1,491 & 0,798 \\
Innovativeness & IN & 540 & 1,00 & 7,00 & 4,869 & 1,309 & 0,848 \\
Proactiveness & PR & 540 & 1,00 & 7,00 & 5,770 & 1,136 & 0,820 \\
Achievement & ACH & 540 & 1,00 & 7,00 & 5,217 & 1,191 & 0,866 \\
\hline Personal attitude & PA & 540 & 1,00 & 7,00 & 4,557 & 1,420 & 0,906 \\
Subjective norm & SN & 540 & 1,00 & 7,00 & 5,074 & 1,309 & 0,807 \\
Perceived behavioural control & PBC & 540 & 1,00 & 7,00 & 4,234 & 1,326 & 0,898 \\
Entrepreneurial intention & EI & 540 & 1,00 & 7,00 & 3,323 & 1,619 & 0,954 \\
\hline Core transformational leader behaviour & L1 & 540 & 1,00 & 7,00 & 5,440 & 1,539 & 0,950 \\
High performance expectations & L2 & 540 & 1,00 & 7,00 & 5,623 & 1,296 & 0,852 \\
Supportive leader behaviour & L3 & 540 & 1,00 & 7,00 & 4,960 & 1,656 & 0,953 \\
Intellectual stimulation & L4 & 540 & 1,00 & 7,00 & 5,137 & 1,590 & 0,957 \\
Contingent reward behaviour & L5 & 540 & 1,00 & 7,00 & 4,920 & 1,689 & 0,943 \\
Contingent punishment behaviour & L6 & 540 & 1,00 & 7,00 & 5,158 & 1,489 & 0,905 \\
\hline Affect & LMX1 & 540 & 1,00 & 5,00 & 3,966 &, 8379 & 0,794 \\
Loyalty & LMX2 & 540 & 1,00 & 5,00 & 3,313 &, 978 & 0,848 \\
Contribution & LMX3 & 540 & 1,00 & 5,00 & 3,925 &, 861 & 0,792 \\
Professional Respect & LMX4 & 540 & 1,00 & 5,00 & 3,967 &, 963 & 0,912 \\
\hline Ethical leadership behaviour & EL & 540 & 1,00 & 5,00 & 3,845 &, 912 & 0,961 \\
\hline Perceived success at work & USP & 540 & 1 & 7 & 5,82 & 1,082 & \\
\hline
\end{tabular}

\subsection{Correlation analysis}

The results of the correlation analysis are shown in Tables II and III. Pearson's correlation was used (the statistically significant correlations were indicated as follows: ${ }^{*} p<0.05 ; * *<0.01$ ).

Table II: Correlation coefficients between the leadership dimensions (transformational and transactional leadership) and individual entrepreneurial orientation dimensions, the achievement dimension and the theory of planned behaviour dimensions $(* p<0.05 ; * * p<0.01)$.

\begin{tabular}{|c|c|c|c|c|c|c|c|c|}
\hline Abbr. & $R T$ & $I N$ & $P R$ & $A C H$ & $P A$ & $S N$ & $P B C$ & $E I$ \\
\hline$L 1$ &, $126 * *$ &, $122 * *$ &, $243 * *$ &, $160 * *$ & 073 & ,083 &, $125^{* *}$ &,- 016 \\
\hline$L 2$ &, $102 *$ &, $093 *$ &, $261 * *$ &, $199 * *$ &, $116 * *$ &, $152^{* * *}$ &, $142 * *$ & ,027 \\
\hline L3 & ,081 & ,090* &, $148 * *$ &, $110 *$ &, 057 &, $087 *$ &, 076 & ,005 \\
\hline L4 &, $120 * *$ &, $111 *$ &, $196 * *$ &, $099 *$ & ,076 &, $114 * *$ &, $105^{*}$ &,- 018 \\
\hline L5 &, $130 * *$ & $158 * *$ & $166^{* *}$ & $156^{* *}$ & 051 & ,092* & ,096* &,- 008 \\
\hline L6 &, 067 & ,086* &, $192 * *$ &, $159 * *$ &, $156 * *$ &, $151 * *$ &, $168 * *$ &, 047 \\
\hline
\end{tabular}

Table III: Correlation coefficients between the leadership dimensions (LMX and ethical leadership) and individual entrepreneurial orientation dimensions, the achievement dimension and the theory of planned behaviour dimensions $(* p<0.05 ; * * p<0.01)$.

\begin{tabular}{|c|c|c|c|c|c|c|c|c|}
\hline Abbr. & $R T$ & $I N$ & $P R$ & $A C H$ & $P A$ & $S N$ & $P B C$ & $E I$ \\
\hline$L M X 1$ &, $172 * *$ &, $186^{* *}$ &, $234^{* *}$ &, $218^{* *}$ &, $101 *$ &, 083 &, $113^{* *}$ &, 047 \\
$L M X 2$ &, $142 * *$ &, $142 * *$ &, $086^{*}$ &, $121^{* *}$ &, 082 &, $095^{*}$ &, $092^{*}$ &, 045 \\
$L M X 3$ &, $121^{* *}$ &, $115^{* *}$ &, $282^{* *}$ &, $249 * *$ &, 083 &, $155^{* *}$ &, $099^{*}$ &,- 004 \\
$L M X 4$ &, $121^{* *}$ &, $121^{* *}$ &, $226^{* *}$ &, $123^{* *}$ &, 069 &, 078 &, $110^{*}$ &, 007 \\
\hline$E L$ &, $122^{* *}$ &, $127^{* *}$ &, $204 * *$ &, $163 * *$ &, 076 &, 059 &, $095^{*}$ &,- 024 \\
\hline
\end{tabular}

\subsection{Regression analysis}

Regression analysis was performed twice: firstly to test the predictive effect of transformational and transactional leadership (Table IV), and secondly to test the predictive effect of LMX and ethical leadership (Table V). (Statistically significant predictive effects are indicated in bold font.) 
Table IV: Regression analysis (independent variables: transformational and transactional leadership dimensions; dependent variables: individual entrepreneurial orientation dimensions, the achievement dimension and the theory of planned behaviour dimensions).

\begin{tabular}{|c|c|c|c|c|c|c|c|c|c|}
\hline \multirow[b]{2}{*}{ Dep. } & \multicolumn{6}{|c|}{ Independent } & \multirow[b]{2}{*}{$R^{2}$} & & \multirow[b]{2}{*}{ Sig. } \\
\hline & $L 1$ & $\begin{array}{c}L 2 \\
\mathrm{St}\end{array}$ & $\begin{array}{c}L 3 \\
\text { lardized }\end{array}$ & $\begin{array}{c}L 4 \\
\text { oeffici }\end{array}$ & $\begin{array}{l}L 5 \\
\text { ts } \beta\end{array}$ & L6 & & & \\
\hline$R T$ & ,071 & ,031 & $\begin{array}{l}-, 098 \\
\end{array}$ & ,044 &, 103 &,- 006 & 0,022 & 2,043 & ,058 \\
\hline$I N$ & ,048 & 01 &,- 080 &,- 027 & 185 & ,023 & 0,028 & 2,592 & ,017 \\
\hline$P R$ & 207 & 148 &,- 081 &,- 014 &,- 017 & ,074 & 0,086 & 8,342 & , 000 \\
\hline$A C H$ & - 096 & ,1 &,- 012 & -,203 & 143 & , 080 & $\mathbf{0 , 0 6 0}$ & 5,633 & ,000 \\
\hline$P A$ & &, 06 &, 020 & 00 &,- 048 & ,13 & $\mathbf{0 , 0}$ & 2,4 & ,022 \\
\hline$S N$ &,- 106 & ,119 & ,034 & ,053 & ,011 & ,095 & 0,034 & 3,086 & ,006 \\
\hline$P B C$ & ,090 & ,053 &,- 043 &,- 024 & , 004 & ,128 & $\mathbf{0 , 0 3 5}$ & 3,217 & ,004 \\
\hline$E I$ &,- 066 & ,050 &, 074 &,- 072 &,- 007 &, 059 & 0,007 & 0,620 & ,714 \\
\hline
\end{tabular}

Table V: Regression analysis (independent variables: LMX and ethical leadership dimensions; dependent variables: individual entrepreneurial orientation dimensions, the achievement dimension and the theory of planned behaviour dimensions).

\begin{tabular}{|c|c|c|c|c|c|c|c|c|}
\hline \multirow[b]{2}{*}{ Dep. } & \multicolumn{5}{|c|}{ Independent } & \multirow[b]{2}{*}{$R^{2}$} & \multirow[b]{2}{*}{$F$} & \multirow[b]{2}{*}{ Sig. } \\
\hline & LMXI & $\begin{array}{l}L M X 2 \\
\text { Standar }\end{array}$ & $\begin{array}{l}L M X 3 \\
\text { ized cos }\end{array}$ & $\begin{array}{c}L M X 4 \\
\text { cients } \beta\end{array}$ & $E L$ & & & \\
\hline$R T$ & ,152 & ,067 & ,027 &,- 012 &,- 037 & $\mathbf{0 , 0 3 3}$ & 3,654 & ,003 \\
\hline$I N$ & 193 & ,057 & ,011 &,- 032 &,- 032 & $\mathbf{0 , 0 3 7}$ & 4,160 & ,001 \\
\hline$P R$ & , 128 &,- 136 & 233 &, 043 & ,022 & $\mathbf{0 , 0 9 8}$ & 11,614 & ,000 \\
\hline $\mathrm{ACH}$ & 207 &,- 048 & ,231 &,- 178 & ,044 & $\mathbf{0 , 0 8 2}$ & 9,544 & ,000 \\
\hline$P A$ & 085 & ,031 & ,037 &,- 028 &,- 004 & 0,012 & 1,291 & 266 \\
\hline$S N$ & ,003 & 054 & 166 &, 007 &,- 074 & $\mathbf{0 , 0 2 7}$ & 2,999 & 011 \\
\hline$P B C$ & 053 & ,032 & 034 & 054 &,- 025 & 0,016 & 1,730 & 126 \\
\hline$E I$ &, 129 & 066 &,- 036 &, 022 &,- 155 & 0,013 & 1,413 & 218 \\
\hline
\end{tabular}

In addition to the results shown in Tables IV and $\mathrm{V}$, data provided by the regression analysis were also used to form regression equations for two particularly significant dependent dimensions: $P A$ - Personal Attitude and $E I-$ Entrepreneurial Intentions. This was done for both regression analyses, and the equations are shown below. On the basis of the unstandardized coefficients $\beta$ (for the independent variables: transformational and transactional leadership dimensions), the multivariate regression dependence model can be set for the dependent variables $P A$ - Personal Attitude and $E I$ - Entrepreneurial Intentions, in the following form:

$$
\begin{aligned}
& \hat{Y}(P A)=3.616+0.000 \cdot L 1+0.065 \cdot L 2+0.017 \cdot L 3+0.002 \cdot L 4-0.041 \cdot L 5+0.131 \cdot L 6 \\
& \hat{Y}(E I)=3.067-0.069 \cdot L 1+0.062 \cdot L 2+0.072 \cdot L 3-0.073 \cdot L 4-0.006 \cdot L 5+0.064 \cdot L 6
\end{aligned}
$$

where the values $L 1$ to $L 6$ are in the interval $[1,7]$.

Similarly, on the basis of the unstandardized coefficients $\beta$ (for the independent variables: LMX and ethical leadership dimensions), the multivariate regression dependence model can be set for the dependent variables $P A$ - Personal Attitude and $E I$ - Entrepreneurial Intentions, in the following form:

$$
\begin{aligned}
& \hat{Y}(P A)=3.786+0.144 \cdot L M X 1+0.044 \cdot L M X 2+0.061 \cdot L M X 3-0.042 \cdot L M X 4-0.006 \cdot E L \\
& \hat{Y}(E I)=3.154+0.249 \cdot L M X 1+0.109 \cdot L M X 2-0.068 \cdot L M X 3+0.038 \cdot L M X 4-0.275 \cdot E L
\end{aligned}
$$

where the values $L M X 1$ to $L M X 4$ and $E L$ are in the interval $[1,5]$.

\subsection{The respondents' perception of success at work as a moderator}

The respondents evaluated their perceptions of their own success at work by assigning scores from 1 to 7 . Given that the respondents perceived their success as relatively high, according to this variable, the sample was divided into those who rated their success at work with scores 
from 1 to 5 (low success) and those who rated their success with scores from 6 to 7 (high success). Thus, the sample consisted of $N L S U C=134$ respondents $(24.8 \%)$ with low success at work $(L S U C)$ and $N H S U C=406$ respondents $(75.2 \%)$ with high success at work $(H S U C)$. First, correlation analysis was carried out for each group separately (Table VI). Pearson's correlation was used, and the statistically significant correlations are indicated as follows: $* p<0.05 ; * * p<0.01$. (Those pairs with moderating effects are shaded.)

Table VI: Correlation coefficients for respondents who perceive their success at work as low (LSUC) and respondents who perceive their success at work as high $(H S U C)\left({ }^{*} p<0.05 ; * * p<0.01\right)$.

\begin{tabular}{|c|c|c|c|c|c|c|c|c|c|}
\hline SUC & Abbr. & $R T$ & $I N$ & $P R$ & $A C H$ & $P A$ & $S N$ & $P B C$ & $E I$ \\
\hline \multirow{11}{*}{ LSUC } & $L 1$ & ,037 & , 108 & $357^{* * *}$ & $248^{* * *}$ &,- 074 & , 145 &,- 049 &,- 244 \\
\hline & $L 2$ & ,020 & 136 &, $428^{* *}$ & , 357 & ,064 & , 160 & ,099 &,- 055 \\
\hline & L3 &,- 137 &,- 004 &, $212^{*}$ & , 105 &,- 081 & ,066 &,- 150 &,$- 219^{*}$ \\
\hline & L4 & ,043 & ,119 & , 334 & ,242 &,- 088 & , 105 &,- 041 &,$- 197^{*}$ \\
\hline & L5 & ,044 & , 148 & $224^{4}$ & $237^{7 * 3}$ &,- 124 & 155 &,- 073 &,$- 225^{*}$ \\
\hline & L6 &,- 028 & ,064 &, $213^{*}$ &, $176^{*}$ & ,069 & ,109 &, $184^{*}$ &,- 050 \\
\hline & $L M X 1$ & , 168 & $253^{* *}$ &, $409^{* *}$ & $277^{* *}$ & ,005 &, $182^{*}$ &,- 023 &,- 161 \\
\hline & $L M X 2$ & ,174* &, $183^{*}$ & 125 &, $172^{*}$ & ,016 &, $172^{*}$ &,- 023 &,- 067 \\
\hline & $L M X 3$ & 154 & , $220^{*}$ & ,346 *** & ,338*** &,- 017 &, $230^{* * *}$ & ,021 &,- 145 \\
\hline & LMX4 & ,089 & ,156 &, $400^{* *}$ & ,207* &,- 058 &, 141 &,- 004 &,- 137 \\
\hline & $E L$ & $182^{*}$ & 269 &, $330^{* * *}$ & $335^{* * i}$ &,- 063 & ,128 &,- 043 &,$- 263^{*}$ \\
\hline \multirow{11}{*}{ HSUC } & L1 & $138^{* *}$ &, $112^{*}$ &, $181^{* *}$ &, $104^{*}$ & $103^{*}$ & ,044 & $158^{*}$ & ,033 \\
\hline & $L 2$ & $107^{*}$ & ,055 &, $158^{* * *}$ & ,099* & $108^{*}$ &, $123^{*}$ &, 126 & ,032 \\
\hline & L3 & $137^{* *}$ & ,108 &, $105^{*}$ & ,090 & ,087 & ,079 & , $128^{*}$ & ,057 \\
\hline & L4 & $132^{* *}$ & ,097, &, $129^{* *}$ & ,030 &, $114^{*}$ &, $103^{*}$ & ,132* & ,020 \\
\hline & L5 & $143^{* *}$ & $149^{* *}$ &, $127^{*}$ &, $109^{*}$ & ,091 &, 056 & $129^{*}$ & ,039 \\
\hline & L6 &, 071 &, 070 &, $154^{* *}$ &, $114^{*}$ & $159^{* * *}$ & $138^{* *}$ & ,136 & ,054 \\
\hline & LMXI & $142^{* *}$ & $136^{* *}$ &, $113^{*}$ & $137^{* * *}$ & ,096 & ,007 &, $112^{*}$ & ,082 \\
\hline & $L M X 2$ & , $120^{*}$ &, $117^{*}$ & ,050 & ,080 & ,086 & ,056 & , 107" & ,063 \\
\hline & $L M X 3$ & ,083 & ,053 & ,219** & $172^{* * *}$ & ,087 & ,098* & ,088 & ,016 \\
\hline & LMX4 & $116^{*}$ & ,095 & $138^{* *}$ & ,066 & ,092 & ,038 &, $124^{*}$ & ,033 \\
\hline & $E L$ &, 085 &, 066 & $132^{* *}$ &, 074 &, $099^{*}$ & ,014 &, $110^{*}$ &, 023 \\
\hline
\end{tabular}

The examination of the moderating effects of the respondents' perceived success at work in the observed relationships was performed using hierarchical regression analysis (Table VII). In this table, only those results for pairs where there are moderating effects are shown: the $R$ square change and $F$-change values in these cases, as well as the correlations of the given pairs for both groups observed.

\subsection{Models of the influence of leadership on entrepreneurial attitudes and intentions among employed persons}

The previously obtained results served to model the influence of the leadership dimensions (transformational, transactional, LMX and ethical leadership) on two particularly significant entrepreneurial dimensions: $P A-$ Personal Attitude and EI - Entrepreneurial Intentions. Based on the results of the correlation analysis (Tables II and III) and those of the regression analysis (Tables IV and V), a general model of the influence of the observed dimensions of leadership on the dimensions $P A$ - Personal Attitude and $E I$ - Entrepreneurial Intentions was formed. This model is shown in Fig. 1.

Similarly, based on the results of the examination of the moderating effect of the respondents' perceived performance at work in the given relationships (Tables VI and VII), a model was also developed for the influence of the observed dimensions of leadership on the dimensions $P A$ - Personal Attitude and $E I$ - Entrepreneurial Intentions for respondents who perceive their success at work as low $(L S U C)$ and respondents who perceive their success at work as high $(H S U C)$. This model is shown in Fig. 2. 
Table VII: Hierarchical regression analysis $(R$ square change, $F$-change and corresponding correlations) of the moderating effects of the respondents' perceived success at work (only those results with moderating effects).

\begin{tabular}{|c|c|c|c|c|c|c|}
\hline \multirow[b]{2}{*}{ Number } & \multirow[b]{2}{*}{ Independent } & \multirow[b]{2}{*}{ Dependent } & \multirow{2}{*}{$\begin{array}{l}R \text { square } \\
\text { change }\end{array}$} & \multirow[b]{2}{*}{$F$-change } & \multicolumn{2}{|c|}{ Correlations } \\
\hline & & & & & $\begin{array}{c}\text { Low success } \\
N_{L S U C}=134\end{array}$ & $\begin{array}{l}\text { High success } \\
N_{H S U C}=406\end{array}$ \\
\hline 1 & $L 1$ & $P R$ & 0,009 & 5,164 &, $357^{* *}$ &, $181^{* *}$ \\
\hline 2 & $L 1$ & $P B C$ & 0,008 & 4,496 &,- 049 & $158^{* * *}$ \\
\hline 3 & $L 1$ & $E I$ & 0,011 & 6,156 &,$- 244^{* *}$ &, 033 \\
\hline 4 & $L 2$ & $P R$ & 0,016 & 9,605 &, $428^{* * *}$ & $158^{* *}$ \\
\hline 5 & $L 2$ & $A C H$ & 0,010 & 6,116 & $357^{* *}$ &, $099^{*}$ \\
\hline 6 & $L 3$ & $R T$ & 0,013 & 7,518 &,- 137 & $137^{* * *}$ \\
\hline 7 & $L 3$ & $P B C$ & 0,013 & 7,479 &,- 150 &, $128^{*}$ \\
\hline 8 & $L 3$ & $E I$ & 0,012 & 6,378 &,$- 219^{*}$ &, 057 \\
\hline 9 & L4 & $P R$ & 0,011 & 6,700 &, $334^{* *}$ & $129^{* * *}$ \\
\hline 10 & L4 & $A C H$ & 0,008 & 4,745 & $242^{* *}$ &, 030 \\
\hline 11 & L4 & $P A$ & 0,007 & 4,080 &,- 088 & $114^{*}$ \\
\hline 12 & L4 & $E I$ & 0,007 & 3,756 &,$- 197^{*}$ & ,020 \\
\hline 13 & L5 & $P A$ & 0,008 & 4,653 &,- 124 & ,091 \\
\hline 14 & L5 & $P B C$ & 0,007 & 4,042 &,- 073 &, $129^{* * *}$ \\
\hline 15 & $L 5$ & $E I$ & 0,010 & 5,721 &,$- 225^{* *}$ &, 039 \\
\hline 16 & $L M X 1$ & $P R$ & 0,019 & 11,552 &, $409^{* * *}$ &, $113^{*}$ \\
\hline 17 & $L M X 1$ & $E I$ & 0,010 & 5,285 &,- 161 &, 082 \\
\hline 18 & $L M X 4$ & $P R$ & 0,017 & 10,251 &, $400^{* *}$ & $138^{* * *}$ \\
\hline 19 & $E L$ & $I N$ & 0,006 & 3,607 & $269^{* *}$ &, 066 \\
\hline 20 & $E L$ & $P R$ & 0,010 & 6,248 &, $330^{* * *}$ & $132^{* * *}$ \\
\hline 21 & $E L$ & $A C H$ & 0,012 & 7,391 &, $335^{* *}$ &, 074 \\
\hline 22 & $E L$ & $E I$ & 0,012 & 6,587 &,$- 263^{* *}$ &, 023 \\
\hline
\end{tabular}

Figs. 1 and 2 show both positive and negative impacts. Also, for both models, statistically significant relations are shown in full lines, while relations that are not statistically significant, but which show a certain impact tendency, are shown by broken lines.

Influental leadership dimensions

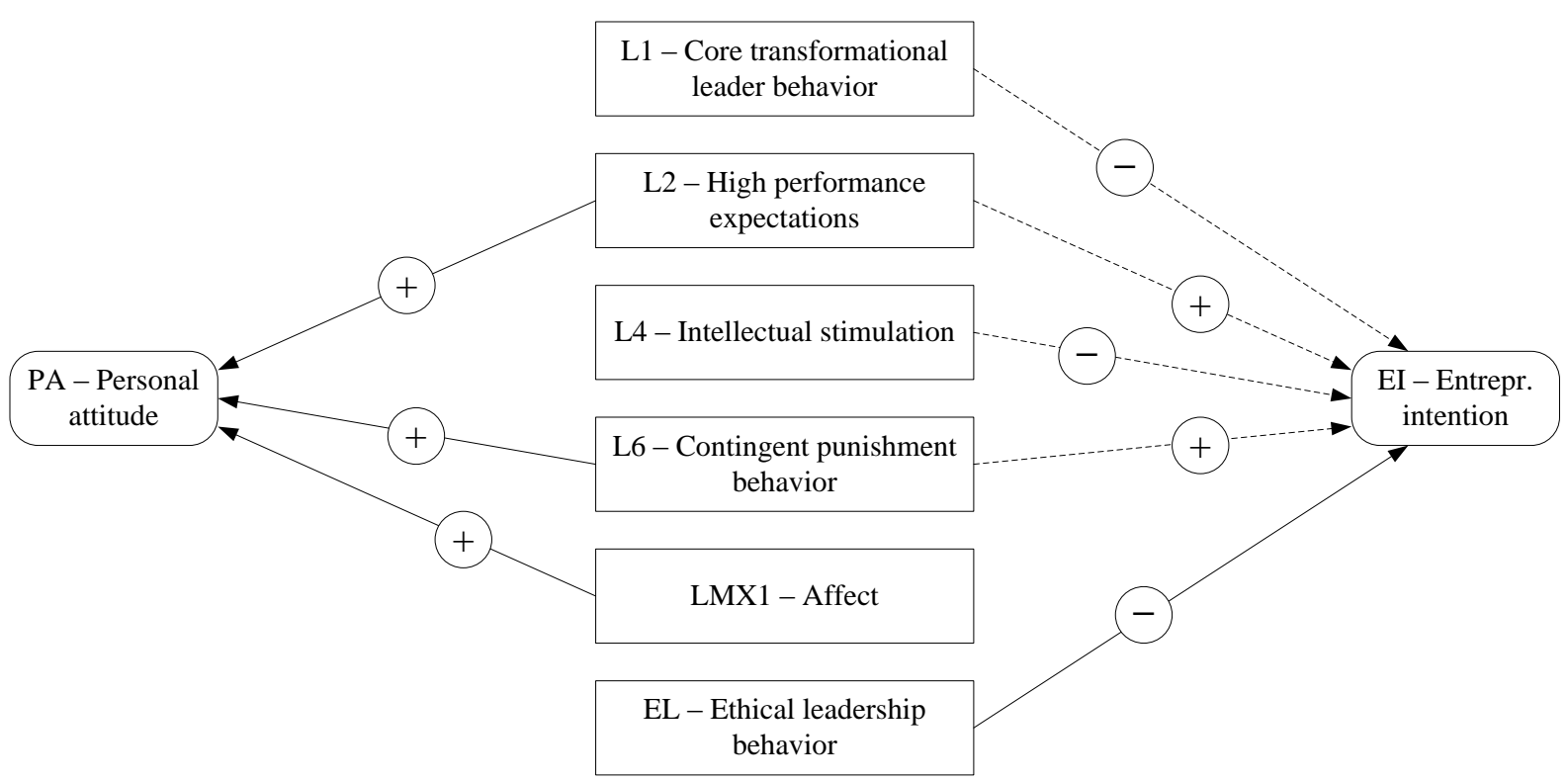

Figure 1: The influence of the leadership dimensions (transformational, transactional, LMX and ethical leadership) on $P A$ - Personal Attitude and $E I$ - Entrepreneurial Intentions. 


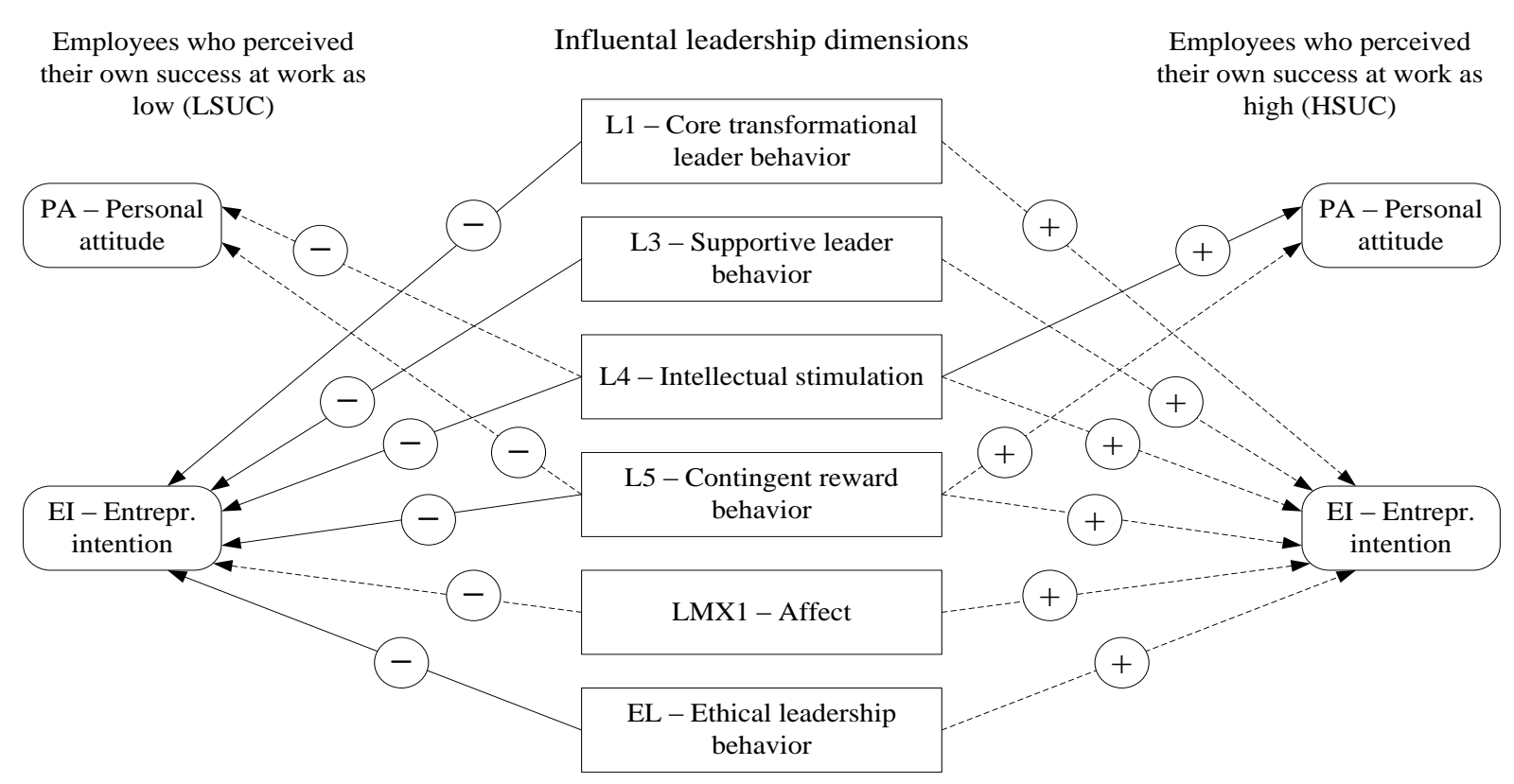

Figure 2: The model of the impact of the leadership dimensions (transformational, transactional, LMX and ethical leadership) on $P A$ - Personal Attitude and EI - Entrepreneurial Intentions for respondents who perceive their success at work as low (LSUC) and respondents who perceive their success at work as high $(H S U C)$.

\section{DISCUSSION}

\subsection{Discussion of the results of the research into the impact of the predictive effect of transformational and transactional leadership (answering RQ1)}

Table II shows that in most cases these leadership dimensions (transformational and transactional leadership) have a statistically significant and positive influence on the dimensions of the observed individual entrepreneurial performances. Dimensions L2 - High Performance Expectations and L6 - Contingent Punishment Behaviour have the strongest impacts. High expectations and punishments have a stimulating effect on employees: they strive to achieve (set high) goals and in that way are likely to avoid punishment, which can certainly be very uncomfortable.

Although dimension EI - Entrepreneurial Intentions does not produce any statistically significant correlations, it can be noted that there is a positive correlation only with dimensions L2 - High Performance Expectations and L6 - Contingent Punishment Behaviour. This certainly points to a certain tendency: the expectation of high performance, with punishment as motivation, arouses positive attitudes towards entrepreneurship, develops the support of the environment (as understanding for the individual in such a situation), and in such conditions the individual finds certain abilities in himself to become an entrepreneur, and finally, the beginning of entrepreneurial intentions is tentatively created. This result shares some similarities with the results of other surveys.

Although the direct impact of dimensions $L 1$ - Core Transformational Leader Behaviour, L4 - Intellectual Stimulation and L5 - Contingent Reward Behaviour on EI - Entrepreneurial Intentions is not statistically significant, it is slightly negative. This suggests a certain tendency: good strategic leadership provides employees with a sense of security, and if all this is accompanied by intellectual stimulation and a fair reward system, employees do not really have any motive to consider the risks of entrepreneurship. On the contrary, mismanagement of the organization, poor intellectual stimulation and unfair rewards can potentially encourage entrepreneurial intentions among employees. 
According to the Table IV, the dimensions L2 - High Performance Expectations and L6 Contingent Punishment Behaviour have the strongest predictive effect, which is fully consistent with the results of the correlation analysis. The corrected determination indexes $R^{2}$ have low values, ranging from 0.007 to 0.086 . However, most of these values are statistically significant. Observed according to individual dependent variables (the dimensions of the observed individual entrepreneurial performances), the dimensions $P R$ - Proactiveness and $A C H$ - Achievement are under the strongest predictive effect of these leadership dimensions (transformational and transactional leadership). This result is consistent with the results of the correlation analysis.

It may be concluded that there is a statistically significant influence and predictive effect of some leadership dimensions (transformational and transactional leadership) on individual entrepreneurial orientation dimensions, the achievement dimension and the theory of planned behaviour dimensions. This provides the answer (affirmative) to research question RQ1.

\subsection{Discussion of the results of the impact of the predictive effects of LMX and ethical leadership (answering RQ2)}

Table III shows that in most cases these leadership dimensions (LMX and ethical leadership) have a statistically significant and positive influence on the dimensions of the observed individual entrepreneurial performances. From these leadership dimensions (LMX and ethical leadership), dimensions $L M X 1$ - Affect and $L M X 3$ - Contribution have the strongest impact. Respect for the leader as a person and the willingness of employees to make significant efforts because of their leaders are the dimensions which may serve to enhance $P R-$ Proactiveness, $A C H$ - Achievement, but also other dimensions.

The dimensions under the greatest influence of these leadership dimensions (LMX and ethical leadership) are those of individual entrepreneurial orientation ( $R T$ - Risk-taking, $I N-$ Innovativeness and $P R$ - Proactiveness) and the $A C H$ - Achievement dimension. Similar to transformational and transactional leadership, dimensions $E I$ - Entrepreneurial Intentions and $P A$ - Personal Attitude are under the weakest influence of these leadership dimensions (LMX and ethical leadership).

The theory of planned behaviour dimensions are not influenced by these dimensions of leadership (LMX and ethical leadership) to the same extent. However, some of them should be noted. Dimension $L M X 1$ - Affect positively influences the dimensions of $P A-$ Personal Attitude and $P B C$ - Perceived Behavioural Control. The dimension $P B C$ - Perceived Behavioural Control has statistically significant correlations with all the other dimensions of leadership (LMX and ethical leadership). Good relations with the leader and ethical leader behaviour serve to encourage employees, giving them a certain sense of security. In such conditions employees perceive their abilities as high, and consequently think that they are also capable of engaging in entrepreneurship.

According to the Table $\mathrm{V}$, the dimensions $L M X 1$ - Affect and $L M X 3$ - Contribution have the strongest predictive effect, which is consistent with the results of the correlation analysis. There is a statistically significant and negative predictive effect of the dimension $E L-$ Ethical Leadership Behaviour on the $E I$ - Entrepreneurial Intentions dimension. In doing so, there is no significant influence of the (un)ethical behaviour of the leader on the $P A$ - Personal Attitude dimension. This relationship shows that there is a greater impact on intentions than on attitudes. Accordingly, the unethical behaviour of the leader can cause great dissatisfaction among employees, which increases entrepreneurial intentions, while attitudes to entrepreneurship may not be so positive.

According to Table $\mathrm{V}$, the corrected determination indexes $R^{2}$ have low values, ranging from 0.012 to 0.098 . However, most of these values are statistically significant. Observed in terms of certain dependent variables (the dimensions of the observed individual 
entrepreneurial performances), those under the strongest predictive effect of these leadership dimensions (LMX and ethical leadership), are $P R$ - Proactiveness and $A C H$ - Achievement. This result is consistent with the results of the correlation analysis.

It may be concluded that there is a statistically significant influence and predictive effect of individual dimensions of leadership (LMX and ethical leadership) on individual entrepreneurial orientation dimensions, the achievement dimension and the theory of planned behaviour dimensions. This provides the answer (affirmative) to research question RQ2.

\subsection{Discussion of the moderating effects of the respondents' perceived success at work (answering RQ3)}

Among employees who perceive their success at work as low, there is a much stronger influence of the leadership dimensions (almost all) on the dimensions of $P R$ - Proactiveness and $\mathrm{ACH}$ - Achievement. At the same time, such conditions do not have a special effect on more successful employees: they do not need (or need significantly less) a leader whom they look up to in order to become proactive and develop the need for achievement.

Among employees who perceive their success at work as low, there is another important phenomenon: the better leadership is, the higher the rewards are, and if the relationship with the leader is better, and the ethical behaviour of the leader is more pronounced, there follows a significant drop in $E I$ - Entrepreneurial Intentions. If the conditions are so good, less successful employees, aware of their low potential, become very satisfied with what they have and lose entrepreneurial intentions. Likewise (but not statistically significant), the $P A-$ Personal Attitude dimension may also decline due to a more pronounced reward system ( $L 5$ Contingent Reward Behaviour).

Among employees who perceive their success at work as high, there is no particular impact of the observed leadership dimensions on the theory of planned behaviour dimensions. Simply put, their $P A$ - Personal Attitude, and $E I$ - Entrepreneurial Intentions in particular, do not depend on leadership to such an extent: good or bad leadership cannot significantly affect their attitudes and intentions, including their entrepreneurial attitudes and intentions. However, the L6 - Contingent Punishment Behaviour dimension, as an extreme measure, can enhance their $P A-$ Personal Attitude.

On this basis, it can be noted that the moderating effect of the respondents' perceived performance at work on the observed relationships exists in a significant number of cases. This provides the answer (mostly confirmed) to research question RQ3.

\section{CONCLUSION}

Dimensions L2 - High Performance Expectations and L6 - Contingent Punishment Behaviour have the strongest impact on the dimensions of the observed individual entrepreneurial performances. Only these two dimensions have a statistically significant (positive) impact on the $P A$ - Personal Attitude dimension. The employees are often motivated by penalties to achieve the expected high results. This is obviously not popular, and dissatisfied with such circumstances, employees begin to feel drawn to entrepreneurship.

Dimension $E I$ - Entrepreneurial Intentions does not produce any statistically significant correlation, but there are certain positive correlations only with L2 - High Performance Expectations and $L 6$ - Contingent Punishment Behaviour. Therefore, in the case of high performance expectations and punishment, employees direct their dissatisfaction towards positive attitudes to entrepreneurship, and to a lesser extent to entrepreneurial intentions.

In addition, the correlation and regression analysis pointed to the tendency of the negative impact of dimensions $L 1$ - Core Transformational Leader Behaviour and $L 4$ - Intellectual Stimulation on $E I$ - Entrepreneurial Intentions. Thus, in favourable conditions (good strategic 
management of the organization and intellectual stimulation), entrepreneurial intentions tend to decline, while under unfavourable conditions (expectation of high performance with punishment as motivation), they have a tendency to increase.

LMX1 - Affect has a statistically significant effect on the $P A$ - Personal Attitude dimension. Respect for the leader as a person can enhance employees' feelings of security, thus providing encouragement, and accordingly, some positive opinions of entrepreneurship may be developed.

The regression analysis pointed to the existence of a statistically significant and negative predictive effect of the $E L$ - Ethical Leadership Behaviour dimension on the EI Entrepreneurial Intentions dimension. At the same time, there is no significant influence of the (un)ethical behaviour of the leader on the dimension $P A$ - Personal Attitude. It is here that there appears to be a stronger impact on entrepreneurial intentions than on attitudes, which clearly indicates the level of dissatisfaction that can be caused by the unethical behaviour of the leader. The results of the correlation and regression analysis enabled the formation of a general model of the impact of the observed leadership dimensions on two particularly significant entrepreneurial dimensions: $P A$ - Personal Attitude and $E I$ - Entrepreneurial Intentions (see Fig. 1).

Among more successful employees, the dimensions of leadership do not exert such a significant influence on entrepreneurial attitudes and intentions. The results of the examination of the moderating effect of the respondents' perceived success at work enabled the formation of the model of the impact of the observed leadership dimensions on the dimensions: $P A$ - Personal Attitude and $E I-$ Entrepreneurial Intentions for respondents who perceive their success at work as low $(L S U C)$ and for those who perceive their success at work as high (HSUC) (see Fig. 2).

The theoretical significance of the paper is that it studies a problem which has not been significantly studied in the literature in the past. The practical significance of the research is reflected in the following recommendation: the state institutions, which are engaged in encouraging and improving entrepreneurship, should also view employees as potential entrepreneurs.

\section{ACKNOWLEDGEMENT}

This paper was supported by the Provincial Secretariat for Science and Technological Development, Autonomous Province of Vojvodina, project number: 142-451-2461/2018-02.

\section{REFERENCES}

[1] Hormiga, E.; Hancock, C.; Valls-Pasola, J. (2013). The relationship between employee propensity to innovate and their decision to create a company, Management Decision, Vol. 51, No. 5, 938-953, doi:10.1108/MD-08-2012-0591

[2] Marshall, D. R.; Gigliotti, R. (2018). Bound for entrepreneurship? A career-theoretical perspective on entrepreneurial intentions, International Entrepreneurship and Management Journal, 17 pages, doi:10.1007/s11365-018-0523-6

[3] Green, A. E.; Miller, E. A.; Aarons, G. A. (2013). Transformational leadership moderates the relationship between emotional exhaustion and turnover intention among community mental health providers, Community Mental Health Journal, Vol. 49, No. 4, 373-379, doi:10.1007/s10597-011-9463-0

[4] Caillier, J. G. (2016). Linking transformational leadership to self-efficacy, extra-role behaviors, and turnover intentions in public agencies: The mediating role of goal clarity, Administration \& Society, Vol. 48, No. 7, 883-906, doi:10.1177/0095399713519093

[5] Sherman, K. E.; Kennedy, D. M.; Woodard, M. S.; McComb, S. A. (2012). Examining the "Exchange" in leader-member exchange, Journal of Leadership \& Organizational Studies, Vol. 19, No. 4, 407-423, doi:10.1177/1548051812442963 
[6] Cho, S.; Johanson, M. M.; Guchait, P. (2009). Employees intent to leave: A comparison of determinants of intent to leave versus intent to stay, International Journal of Hospitality Management, Vol. 28, No. 3, 374-381, doi:10.1016/j.ijhm.2008.10.007

[7] Liu, C.-M.; Chiu, C.-K. (2018). Modeling turnover intention and job performance: the moderation of perceived benevolent climate, Review of Managerial Science, 21 pages, doi: $10.1007 / \mathrm{s} 11846-018-0302-3$

[8] Rubel, M. R. B.; Kee, D. M. H.; Quah, C. H.; Rimi, N. N. (2017). Ethical climate and employee turnover intention in the ready-made garment industry of Bangladesh, Global Business and Organizational Excellence, Vol. 36, No. 2, 61-73, doi:10.1002/joe.21770

[9] Vukonjanski, J.; Nikolić, M.; Hadžić, O.; Terek, E.; Nedeljković, M. (2012). Relationship between GLOBE organizational culture dimensions, job satisfaction and leader-member exchange in Serbian organizations, Journal for East European Management Studies, Vol. 17, No. 3, 333-368

[10] Sajfert, D.; Nikolić, M.; Vukonjanski, J.; Terek, E.; Vulović, M. (2017). The impact of leaders' ethical behavior on certain individual and organizational effects: the Serbian case, Journal for East European Management Studies, Vol. 22, No. 4, 444-483, doi:10.5771/0949-6181-2017-4$\underline{444}$

[11] Miller, D. (1983). The correlates of entrepreneurship in three types of firms, Management Science, Vol. 29, No. 7, 770-791, doi:10.1287/mnsc.29.7.770

[12] Robinson, S.; Stubberud, H. A. (2014). Elements of entrepreneurial orientation and their relationship to entrepreneurial intent, Journal of Entrepreneurship Education, Vol. 17, No. 2, 1-11

[13] Brandstätter, H. (2011). Personality aspects of entrepreneurship: A look at five meta-analyses, Personality and Individual Differences (Special Issue on Personality and Economics), Vol. 51, No. 3, 222-230, doi:10.1016/j.paid.2010.07.007

[14] Rezaei Zadeh, M.; Hogan, M.; O’Reilly, J.; Cunningham, J.; Murphy, E. (2017). Core entrepreneurial competencies and their interdependencies: insights from a study of Irish and Iranian entrepreneurs, university students and academics, International Entrepreneurship and Management Journal, Vol. 13, No. 1, 35-73, doi:10.1007/s11365-016-0390-y

[15] Marič, M.; Miglič, G.; Jordan, G. (2017). The impact of authentic leadership on psychological empowerment of the employees in the Slovenian local self-government institutions, Lex Localis Journal of Local Self-Government, Vol. 15, No. 3, 625-645, doi:10.4335/15.3.625-645(2017)

[16] Strukan, E.; Nikolić, M.; Sefić, S. (2017). Impact of transformational leadership on business performance, Technical Gazette, Vol. 24, Suppl. 2, 435-444, doi:10.17559/TV-20150624082830

[17] Copus, C.; Steyvers, K. (2017). Local leadership and local-self government: avoiding the abyss, Lex Localis - Journal of Local Self-Government, Vol. 15, No. 1, 1-18, doi:10.4335/15.1.1$\underline{18(2017)}$

[18] Ajzen, I. (1991). The theory of planned behavior, Organizational Behavior and Human Decision Processes, Vol. 50, No. 2, 179-211, doi:10.1016/0749-5978(91)90020-T

[19] Bolton, D. L.; Lane, M. D. (2012). Individual entrepreneurial orientation: development of a measurement instrument, Education + Training, Vol. 54, No. 2/3, 219-233, doi: $10.1108 / 00400911211210314$

[20] Athayde, R. (2009). Measuring enterprise potential in young people, Entrepreneurship Theory and Practice, Vol. 33, No. 2, 481-500, doi:10.1111/j.1540-6520.2009.00300.x

[21] Liñán, F.; Chen, Y.-W. (2009). Development and cross-cultural application of a specific instrument to measure entrepreneurial intentions, Entrepreneurship Theory and Practice, Vol. 33, No. 3, 593-617, doi:10.1111/j.1540-6520.2009.00318.x

[22] MacKenzie, S. B.; Podsakoff, P. M.; Rich, G. A. (2001). Transformational and transactional leadership and salesperson performance, Journal of the Academy of Marketing Science, Vol. 29, No. 2, Paper 115, doi:10.1177/03079459994506

[23] Liden, R. C.; Maslyn, J. M. (1998). Multidimensionality of leader-member exchange: An empirical assessment through scale development, Journal of Management, Vol. 24, No. 1, 43-72, doi: $10.1177 / 014920639802400105$

[24] Brown, M. E.; Trevino, L. K.; Harrison, D. A. (2005). Ethical leadership: A social learning perspective for construct development and testing, Organizational Behavior and Human Decision Processes, Vol. 97, No. 2, 117-134, doi:10.1016/j.obhdp.2005.03.002 